\title{
The Protective Role of N,N-Dimethylthiourea and lits Effect on Hydrogen Peroxide Level of Hela Kyoto Cells under Cisplatin Action
}

DOI: $10,17691 / \mathrm{stm} 2018.10 .3 .9$

Received February 22, 2018

A.S. Nerush, Junior Researcher, Laboratory of Biophotonics ${ }^{1}$;

K.M. Shchukina, Student, Department of Biophysics;

A.G. Orlova, PhD, Senior Researcher, Laboratory of Biophotonics ${ }^{1}$

Federal Research Center Institute of Applied Physics of the Russian Academy of Sciences, 46 Ul'yanova St., Nizhny Novgorod, 603950, Russia;

2Lobacheysky State University of Nizhni Novgorod, 23 Prospekt Gagarina, Nizhny Novgorod, 603950, Russia

The aim of the study is to sense the level of hydrogen peroxide $\left(\mathrm{H}_{2} \mathrm{O}_{2}\right)$ in viable and apoptotic HeLa Kyoto cells under the action of cisplatin in presence of reactive oxygen species scavenger N,N'-dimethylthiourea (DMTU).

Materials and Methods. HeLa Kyoto cell line transfected with hydrogen peroxide sensor HyPer2 or pH sensor SypHer2 was incubated with cisplatin for $24 \mathrm{~h}$ with or without DMTU. The viability of the cells was determined by trypan blue staining technique and flow cytometry with apoptosis marker and vital dye. The response of the sensors was determined in viable cells and in cells in early apoptosis separately.

Results. A decrease in the percentage of viable cells upon exposure to cisplatin inhibited by the addition of DMTU to the incubation medium was shown. A significant increase in $\mathrm{H}_{2} \mathrm{O}_{2}$ level in HeLa Kyoto cells was observed upon drug exposure, while incubation with cisplatin and DMTU simultaneously resulted in a value close to the control one. The observed reaction was typical for both viable and apoptotic cells.

Conclusion. The protective role of DMTU and the involvement of $\mathrm{H}_{2} \mathrm{O}_{2}$ in tumor cells death under the cisplatin action was proved.

Key words: HeLa Kyoto; fluorescent sensor; HyPer2; SypHer2; cisplatin; hydrogen peroxide; N,N'-dimethylthiourea.

\section{Introduction}

Cisplatin is a platinum-containing chemotherapeutic drug successfully used in treatment of a wide range of tumors such as carcinomas, lymphomas, sarcomas, germinogenic tumors, etc. [1, 2]

Along with direct action on DNA, this agent causes the formation of reactive oxygen species (ROS), including hydrogen peroxide $\left(\mathrm{H}_{2} \mathrm{O}_{2}\right)[3,4]$. Hydrogen peroxide is of particular interest among other ROS due to its participation in apoptosis of tumor cells. $\mathrm{H}_{2} \mathrm{O}_{2}$ mediates apoptosis by inhibiting the expression of $\mathrm{Bcl}-2$ [5], as well as caspases activation and Bax expression [6-8]. In this connection, the study of hydrogen peroxide potential role in cisplatin-induced apoptosis of tumor cells is important for development of novel safe and efficient therapeutic strategies against oncological diseases.

The study of intracellular $\mathrm{H}_{2} \mathrm{O}_{2}$ level changes is associated with a number of difficulties in measurement procedure. Recently, specific fluorescent probes have been developed, sensitive to $\mathrm{H}_{2} \mathrm{O}_{2}$ due to the ability to fluoresce upon oxidation of $\mathrm{H}_{2} \mathrm{O}_{2}$. These probes have a number of limitations related to low selectivity or irreversibility of the reaction with $\mathrm{H}_{2} \mathrm{O}_{2}$ [9]. Genetically encoded sensor HyPer is free of these disadvantages. This sensor based on the peroxide sensitive domain Oxy-R and the yellow fluorescent protein has high selectivity and sensitivity, demonstrates direct expression in cells, and allows for easy targeting to various subcellular compartments [10]. Recently this sensor was applied to study hydrogen peroxide level in transfected tumor cells under the action of chemotherapy [11], photodynamic therapy [12], growth factors [13], and in macrophages during phagocytosis [14]. These studies employed fluorescence microscopy for assessment of the sensor reaction. Previously we proposed a novel approach based on flow cytometry to study the hydrogen peroxide level in cells expressing HyPer family sensor [15]. This approach allows estimating $\mathrm{H}_{2} \mathrm{O}_{2}$ level separately in viable cells and in cells in the stage of early apoptosis. The proposed approach was approbated in the study of cell death mechanisms of and sensor response under cisplatin and bleomycin action on tumor cells.

Corresponding author: Anastasia S. Nerush, e-mail: nerush-as@mail.ru 
To confirm the connection of the sensor activation with cisplatin-induced cell death, it is necessary to induce the reduction of $\mathrm{H}_{2} \mathrm{O}_{2}$ content inside a cell, which should lead to an absence of sensor response and an increase in the percentage of viable cells upon addition of cisplatin. For this purpose, in this study, we employed ROS scavenger N,N'-dimethylthiourea (DMTU). DMTU is a highly efficient absorber of $\mathrm{OH}^{\circ},{ }^{1} \mathrm{O}_{2}[16,17]$, and $\mathrm{H}_{2} \mathrm{O}_{2}$ [18], known to decrease the $\mathrm{H}_{2} \mathrm{O}_{2}$-induced damage of cultured endothelial cells [19], to reduce the cisplatin-induced tumor necrosis factor-alpha (TNF- $\alpha$ ) expression in macrophages in vitro, and to prevent the development of oxidative stress, activation of p53 and, as a consequence, apoptosis of renal and hepatic cells in vivo [20-23]. An important step is to carry out experiments on cytotoxicity of cisplatin under conditions of hydrogen peroxide removal from cells using DMTU. To confirm that DMTU, along with other ROS, reduces the hydrogen peroxide content under cisplatin action, in this study its level was controlled with the specific sensor HyPer2 in parallel with the cytotoxic tests. This approach allows the determination of the role of $\mathrm{H}_{2} \mathrm{O}_{2}$ in the process of cisplatin-induced cell death.

The aim of the study is to sense the level of hydrogen peroxide in viable and apoptotic HeLa Kyoto cells under the action of cisplatin in the presence of reactive oxygen species scavenger N,N'-dimethylthiourea.

\section{Materials and Methods}

Cell lines. The study was performed with HeLa Kyoto, the human cervical carcinoma cell line transfected with cytoplasmic sensor HyPer2 (a HyPer modification with an extended dynamic range). This sensor has a high sensitivity to changes in the hydrogen peroxide level in cells [13], however, like most fluorescent proteins, is $\mathrm{pH}-$ sensitive, which necessitated the intracellular $\mathrm{pH}$ control. In this connection, the HeLa Kyoto cell line transfected with hydrogen peroxide insensitive HyPer2 analogue SypHer2 [24], was used. Cell lines were obtained from the M.M. Shemyakin and Yu.A. Ovchinnikov Institute of Bioorganic Chemistry of the Russian Academy of Sciences.

The cells were cultured in Dulbecco's Modified Eagle Medium (DMEM) (PanEco, Russia), supplemented with $2 \mathrm{mM}$ glutamine and $10 \%$ fetal bovine serum (HyClone, USA) in a $\mathrm{CO}_{2}$ incubator at $37^{\circ} \mathrm{C}$ in a humidified atmosphere with $5 \% \mathrm{CO}_{2}$.

Staining with trypan blue. Cells were seeded into 12-well plates at $1 \cdot 10^{5}$ cells per well a day before the experiment. On the next day, they were treated with 16.6 $\mu \mathrm{M}$ cisplatin, the concentration corresponding to 2 -fold $\mathrm{IC}_{50}\left(\mathrm{IC}_{50}\right.$ causes inhibition of $50 \%$ of cells) [25] in the presence or absence of $15 \mathrm{mM}$ DMTU (Sigma-Aldrich, USA). Cells without addition of cisplatin to incubation solution served as a control group. The incubation was carried out for $24 \mathrm{~h}$, after which the medium with the cells was placed into centrifuge tubes, the cells were washed off from the well with a cold phosphate-buffered saline (PBS) twice and then centrifuged for 5 min with Refrigerated Centrifuge 5810 (Eppendorf, Germany) at $900 \mathrm{rpm}$. After centrifugation, $0.4 \%$ trypan blue solution was added to the cells suspended in PBS solution in a 1:1 ratio. Goryaev's camera was used to count the stained and unstained cells.

Flow cytometry with apoptosis markers. Cells were plated on 12 -well plates at $1 \cdot 10^{5}$ cells per well a day before the experiment. On the next day, they were exposed to $16.6 \mu \mathrm{M}$ cisplatin in the presence or absence of $15 \mathrm{mM}$ DMTU. Cells without addition of cisplatin to incubation solution served as control cells. After $24 \mathrm{~h}$ of incubation with the drug, the medium with the cells was taken into centrifuge tubes, the cells were washed off from the well with cold PBS solution twice. Annexin binding buffer in the amount of $1.5 \cdot 10^{6}$ cells/ $\mathrm{ml}$ was added to the cells precipitated by centrifugation for 5 min with Refrigerated Centrifuge 5810 (Eppendorf, Germany) at $900 \mathrm{rpm}, 1.5 \cdot 10^{5}$ cells were transferred to tubes for flow cytometry.

To analyze the fluorescence of sensors in viable cells and cells in the early apoptosis the approach [15] was used. This approach allows for simultaneous assessment of cell death pathways and hydrogen peroxide content in each cell using the marker for Annexin $V$ labeled with phycoerythrin $(\mathrm{PE})$, the vital dye 7-amino-actinomycin $\mathrm{D}$ (7-AAD) and the sensor for $\mathrm{H}_{2} \mathrm{O}_{2}$. To analyze the pathways of cell death PE Annexin $V$ Apoptosis Detection Kit I (BD Biosciences, USA) was used. PE Annexin V and 7-AAD in the amount of $5 \mu \mathrm{l}$ each were added to each probe, each probe shaken for 1-2 s with minicentrifuge/ vortex Microspin FV-2400 (BioSan, Latvia) and incubated in the dark at $25^{\circ} \mathrm{C}$ for $15 \mathrm{~min}$.

Probes were transferred to the cold, $400 \mu \mathrm{l}$ of Annexin binding buffer was added to the cells prior to fluorescence detection. The change in fluorescence intensities of dyes and the response of genetically encoded sensors were recorded with a flow cytometer FACSCalibur (Becton Dickinson, USA) employing laser excitation at the wavelength of $488 \mathrm{~nm}$ and three detection channels with filters 530/30 nm (fluorescence of HyPer2 and SypHer2, FL1 channel), 585/42 nm (fluorescence of PE Annexin V, FL2 channel), 670 LP (fluorescence 7-AAD, FL3 channel). In each probe $1.5 \cdot 10^{4}$ cells were analyzed.

Data processing. For assessing cell viability by trypan blue staining 5 experiments were carried out on the HeLa Kyoto-HyPer2 cells and 3 experiments on the HeLa Kyoto-SypHer2 cells. Data was processed using Excel 2016 software (Microsoft, USA) and presented as mean values and standard deviations. To determine the statistical significance of differences between groups a one-factor analysis of variance with the post-hoc Bonferroni test for multiple comparisons in Statistica 6.0 (StatSoft, USA) was used. To calculate the percentage of viable, early apoptotic and dead cells, as well as median fluorescence intensities of the sensors obtained 
by flow cytometry, BD CellQuest ${ }^{\mathrm{TM}}$ Pro Software (Becton Dickinson, USA) was used.

\section{Results}

The results of staining of HeLa Kyoto-HyPer2 cells with trypan blue (Figure 1 (a)) demonstrated a statistically significant decrease in the percentage of viable cells after cisplatin treatment from $74.2 \pm 9.2$ to $29.1 \pm 15.6 \% \quad(p<0.0001)$ as compared to control (cisplatin untreated cells). However, this effect was not observed when DMTU was added to the incubation medium simultaneously with cisplatin, which resulted in a statistically significant $(p<0.001)$ increase in the number of living cells up to $71.5 \pm 13.2 \%$ as compared to cells treated with cisplatin only. It should be noted that the addition of DMTU to untreated cisplatin cells did not adversely affect the viability of this cell line amounting to $77.7 \pm 8.1 \%$.

Staining of HeLa Kyoto-SypHer2 cells with trypan blue (Figure 1 (b)) showed similar results: addition of cisplatin leads to a statistically significant decrease in the percentage of viable cells from $82.5 \pm 7.3$ to $26.5 \pm 17.6 \%(p<0.01)$ as compared to cisplatin untreated cells. When DMTU was added to the incubation medium simultaneously with cisplatin, a statistically significant increase in the percentage of viable cells was observed up to $68.7 \pm 13.7 \%(p<0.05)$ as compared with cisplatinonly treated cells, which indicates the elimination of the cisplatin effect by DMTU.

Further flow cytometry with the staining of cells with an apoptosis marker and a vital dye enabled the identification of three cell populations: viable cells that are negative for 7-AAD and PE Annexin V, cells in the early apoptosis that are positive for PE Annexin $V$ and negative for 7-AAD, and cells in late apoptosis or necrosis (dead cells) that are positive for both dyes, as well as the ones that are 7-AAD positive cells and negative for PE Annexin $V$ (Figures 2, 3).

Flow cytometry showed that the addition of cisplatin to HeLa Kyoto-HyPer2 cells line leads to a significant increase in the number of dead cells, from 17.7 to $73.6 \%$ (Figure 2 (a), (b)), without increasing the number of cells passing the stage of early apoptosis: $10.8 \%$ in the control and $9.9 \%$ in cells treated with cisplatin only. The number of viable cells after addition of cisplatin decreases for more than $50 \%$ : from 71.5 to $16.6 \%$. It was shown that the simultaneous incubation of cells with cisplatin and DMTU leads to an increase in the percentage of viable cells from 16.6 to $76.8 \%$ (Figure 2 (b), (d)), while the percentage of cells in early apoptosis changes insignificantly and is equal to that in the control. Treatment with DMTU of the cells that were not exposed to cisplatin did not adversely affect the viability of this cell line.

Staining of the control cell line HeLa Kyoto-SypHer2 with 7-AAD and PE Annexin $V$ demonstrated similar results (see Figure 3 ): treatment of cells with DMTU and cisplatin caused an increase in the percentage of viable cells from 11.9 to $61.8 \%$ and decrease in the percentage of cells passing the early apoptosis from 24.4 to $8.1 \%$. Treatment with DMTU of the cells that were not exposed to cisplatin also did not affect the viability of the cell line.

Employment of the apoptosis marker and the vital dye allowed to construct fluorescence histograms of HyPer2 sensors (left column) and SypHer2 (right column) for the whole cell population (Figure 4 (a), (b)), and separately for living cells (Figure 4 (c), (d)) and for cells in stage of early apoptosis (Figure 4 (e), (f)).

The histogram of HyPer2 fluorescence (see Figure 4 (a)) plotted for all cells shows an increase in the fluorescence intensity of cisplatin-treated cells relative to control cells, which decreases with the addition of DMTU. Similar histograms plotted for the

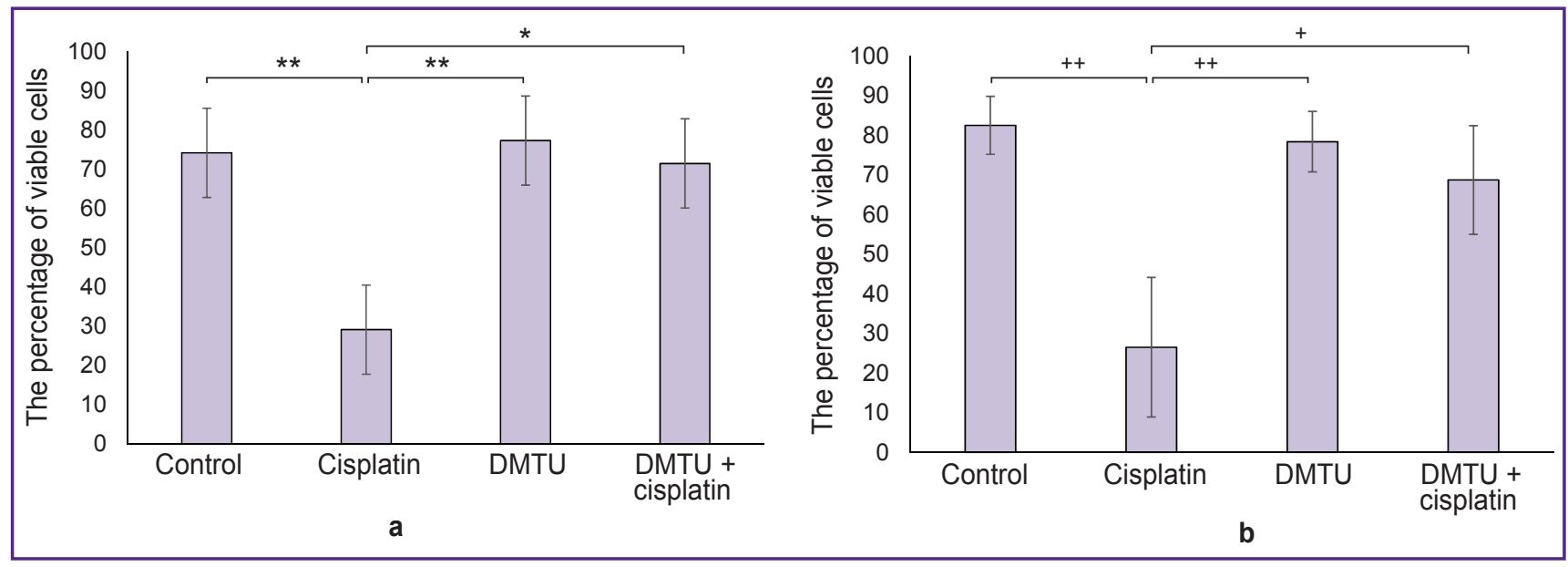

Figure 1. The percentage of viable cells after exposure with $16.6 \mu \mathrm{M}$ cisplatin and/or $15 \mathrm{mM}$ DMTU for $24 \mathrm{~h}$ (results of staining with trypan blue):

(a) HeLa Kyoto-HyPer2; ${ }^{p} p<0.001,{ }^{* *} p<0.0001$; (b) HeLa Kyoto-SypHer2; ${ }^{+} p<0.05,{ }^{++} p<0.01$ 


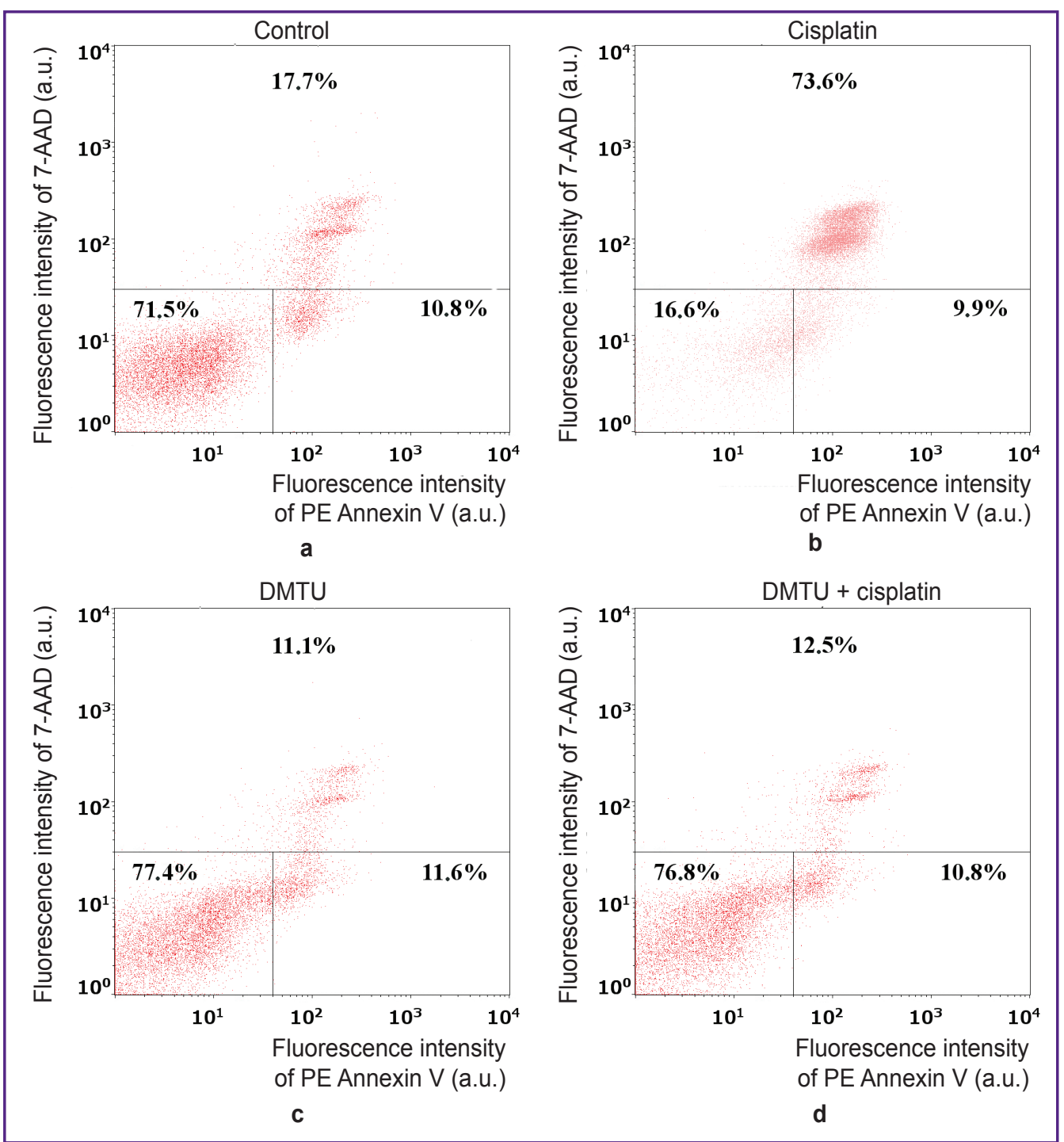

Figure 2. Distribution of HeLa Kyoto-HyPer2 cells over fluorescence intensity of 7-AAD and PE Annexin V:

(a) without addition of cisplatin and DMTU; (b) after exposure to $16.6 \mu \mathrm{M}$ cisplatin; (c) after exposure to $15 \mathrm{mM} \mathrm{DMTU;} \mathrm{(d)} \mathrm{after} \mathrm{exposure} \mathrm{to} 16.6 \mu \mathrm{M}$ cisplatin and $15 \mathrm{mM}$ DMTU (24 $\mathrm{h}$ of incubation); viable cells are located in the left lower quadrant; cells undergoing early apoptosis are in the right lower quadrant, and dead cells are in the left and right upper quadrants

cell line containing SypHer2 (see Figure 4 (b)) shows a decrease in fluorescence intensity of cisplatintreated cells as compared to untreated control cells; upon DMTU addition the fluorescence intensity returns to the values of the control cells. A part of the cell population characterized by low fluorescence intensity of the sensors (up to $\sim 100$ a.u., see Figure 4 (a), (b)), that was strongly stained with 7-AAD, was identified as dead cells and was excluded from the analysis (data not shown). In the histograms constructed for living cells and cells in the early apoptosis, a region for estimating the median fluorescence intensity of the sensors (M1) was selected. This allowed us to estimate the difference in the fluorescence of different cell probes.

The addition of DMTU resulted in a slight decrease in the median fluorescence intensity of the sensor from 221 to 215 a.u. in viable HeLa Kyoto-HyPer2 cells, while in viable cells containing SypHer2 it caused a slight increase in the median fluorescence intensity of the sensor from 389 to 414 a.u. (Figure 4 (c), (d)). The addition of cisplatin to cells containing HyPer2 resulted in a twofold increase in the median fluorescence intensity up to 461 a.u., while in the cell line containing SypHer2 the incubation with cisplatin caused a decrease in the median fluorescence intensity of the 


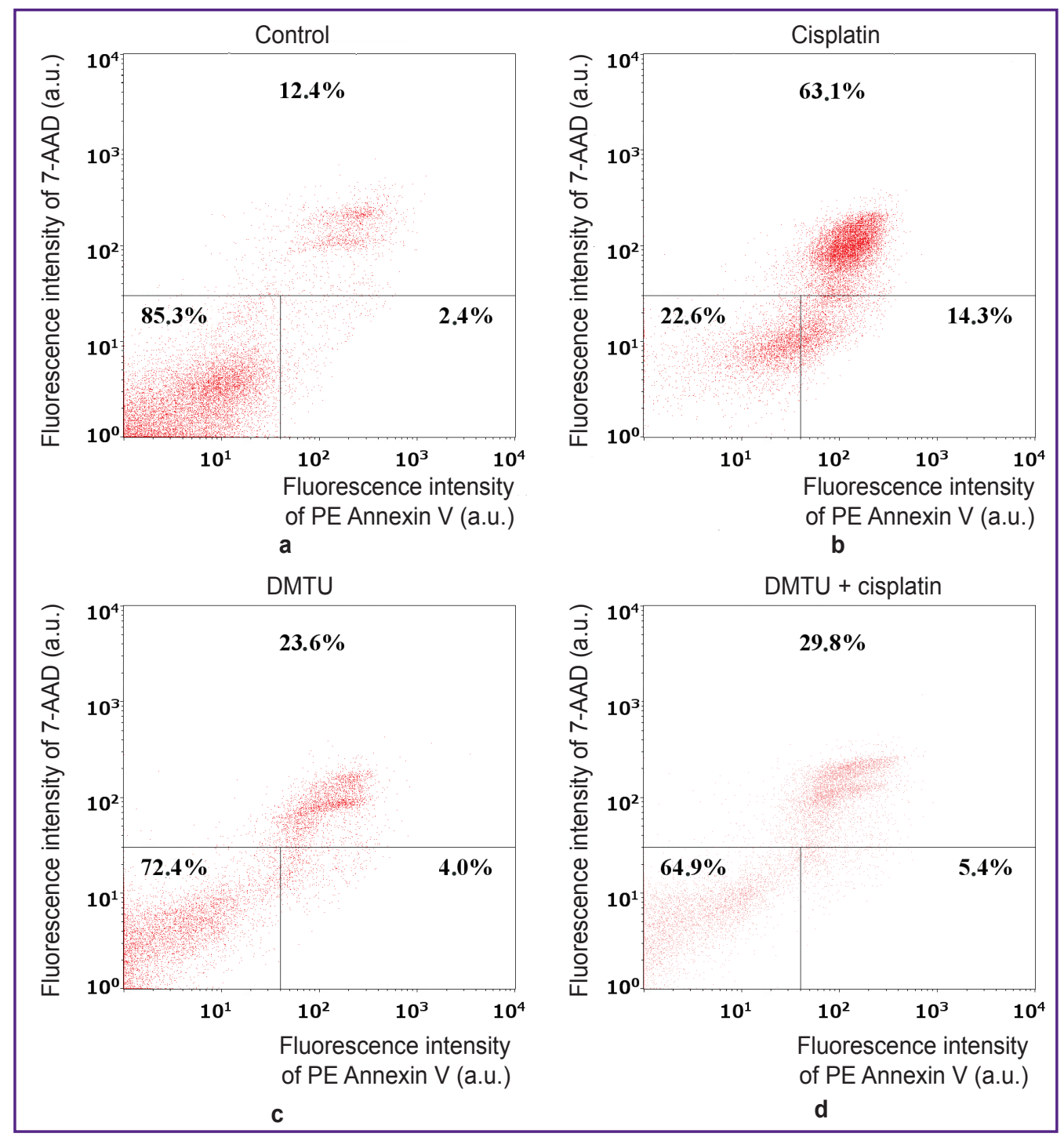

Figure 3. Distribution of HeLa Kyoto-SypHer2 cells over fluorescence intensity of 7-AAD and PE Annexin V:

(a) without addition of cisplatin and DMTU: (b) after exposure to $16.6 \mu \mathrm{M}$ cisplatin; (c) after exposure to $15 \mathrm{mM}$ DMTU; (d) after exposure to $16.6 \mu \mathrm{M}$ cisplatin and $15 \mathrm{mM}$ DMTU (24 $\mathrm{h}$ of incubation); viable cells are located in the left lower quadrant; cells undergoing early apoptosis are in the right lower quadrant, and dead cells are in the left and right upper quadrants

sensor down to 300 a.u. Addition of DMTU with cisplatin simultaneously caused a decrease in the median fluorescence intensity of the sensor HyPer2 to 235 a.u., however, for SypHer2 this decrease was not observed (453 a.u.). In both cases, the shape of the fluorescence peak for cells with the addition of DMTU is similar to that for control cells.

In populations of cells passing the stage of early apoptosis (Figure 4 (e), (f)), the addition of DMTU caused a decrease in the median fluorescence intensity in both lines. The addition of cisplatin to HeLa KyotoHyPer2 cells caused an almost double increase in the median value, from 170 to 331 a.u., while the addition of the same drug to HeLa Kyoto-SypHer2 cells resulted in a significant decrease in the median fluorescence intensity of the sensor from 422 to 294 a.u. Simultaneous incubation with DMTU and cisplatin resulted in a decrease in the median fluorescence intensity below the median values for cells treated with cisplatin only. This effect was observed both in the HeLa Kyoto-HyPer2 cell line (160 a.u.), and in the HeLa Kyoto-SypHer2 cell line (198 a.u).

It should be noted that for all cell probes that underwent simultaneous incubation with DMTU and cisplatin the peaks have similar shape with those for cell probes treated with DMTU only. 


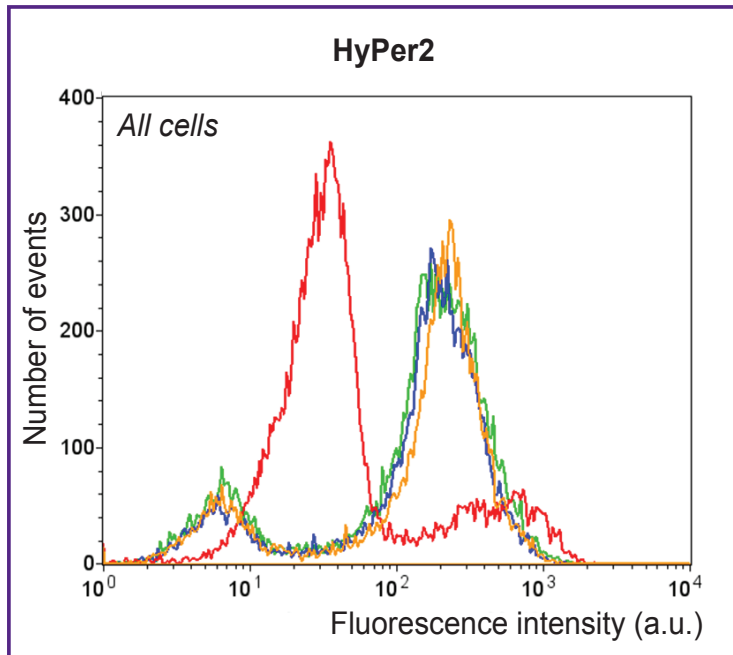

a

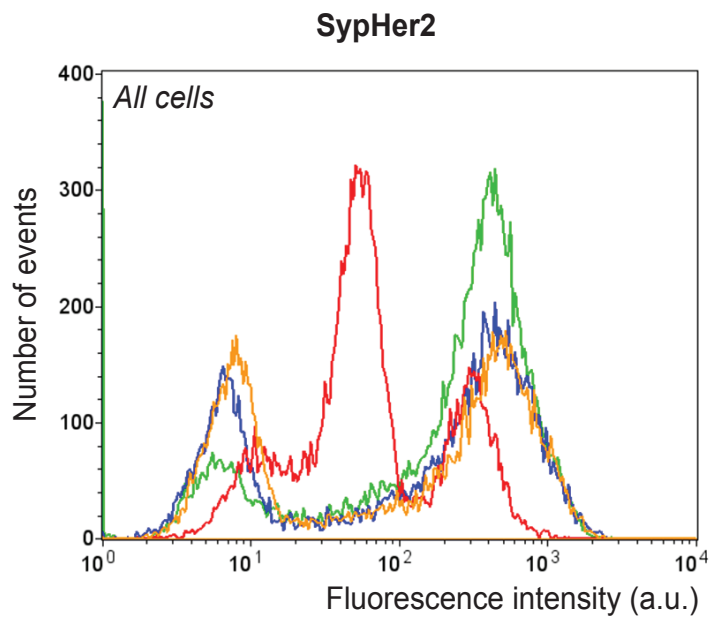

b
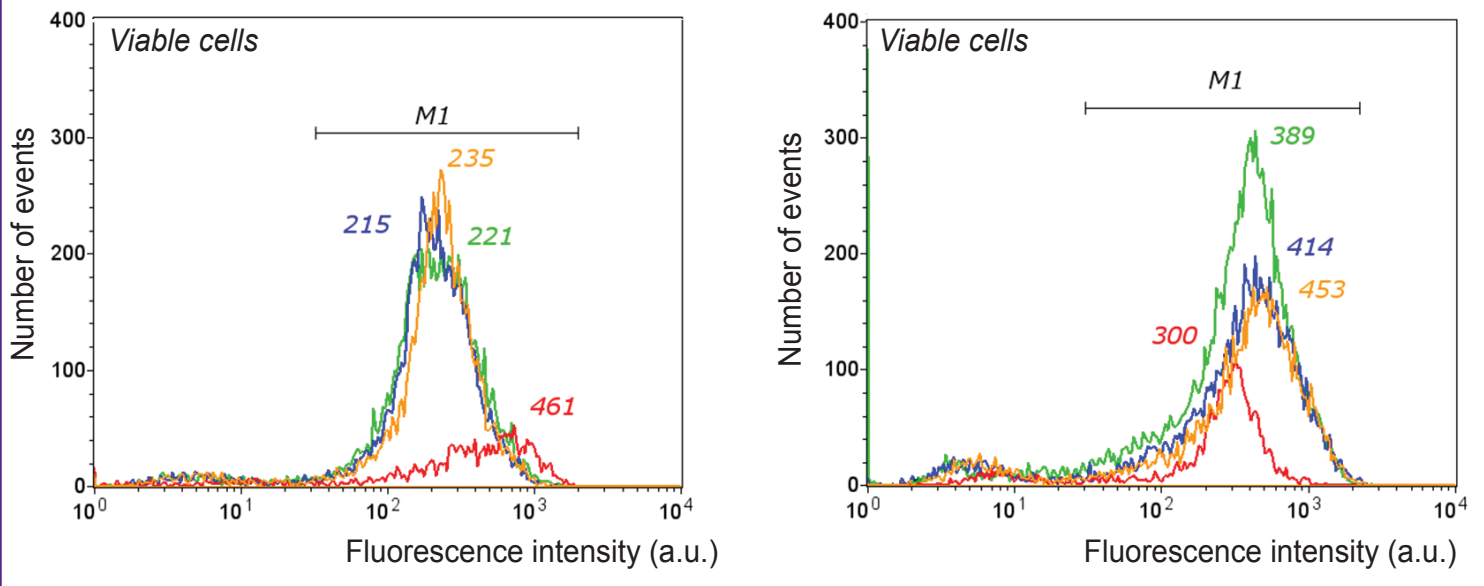

c
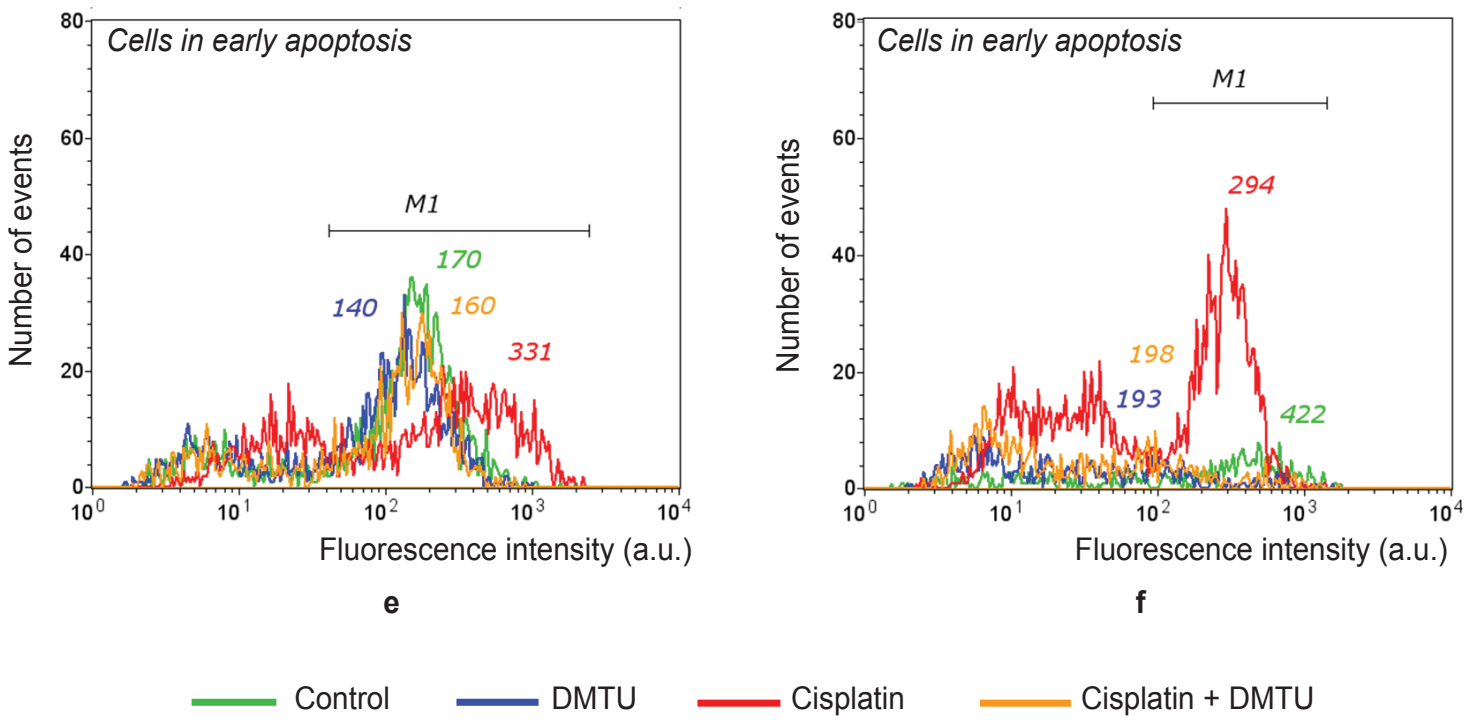

Cisplatin

Cisplatin + DMTU

Figure 4. Histograms of the fluorescence of HeLa Kyoto-HyPer2 (a), (c), (e) and HeLa Kyoto-SypHer2 (b), (d), (f) under the action of cisplatin and/or DMTU, plotted for different cell populations:

(a), (b) all cells; (c), (d) viable cells; (e), (f) cells in the early apoptosis stage. Division to cell populations is based on the cells distribution of over the fluorescence intensity of 7-AAD and PE Annexin V shown in Figures 2, 3. M1 is the area of determination of the sensors fluorescence intensity median value 


\section{Discussion}

Analysis of diagrams of the staining of HeLa KyotoHyPer2 and HeLa Kyoto-SypHer2 cells with trypan blue (see Figure 1), indicated that the reactions of both cell lines to the addition of cisplatin and/or DMTU are similar: incubation for $24 \mathrm{~h}$ with $16.6 \mu \mathrm{M}$ cisplatin leads to the death of about $50 \%$ of cells, and this effect can be neutralized by adding $15 \mathrm{mM}$ DMTU to the incubation medium. The ROS scavenger DMTU added to cisplatin significantly increases the survival rate of the drugtreated cells, indicating that an increase in the level of intracellular ROS mediates cisplatin-induced death of tumor cells. Addition of DMTU only did not cause any significant changes in cells viability.

The distribution of cells of both lines according to 7-AAD and PE Annexin $V$ fluorescence intensity (see Figures 2, 3) also indicated the similarity of their responses to cisplatin, proving that the differences in the structure of the sensors did not affect significantly the functional state of the cells. It should be noted that in both cell lines, the majority of the dying cells initially moved from the quadrant of the diagram typical for living cells to the quadrant typical for early apoptotic cells, and only then migrate to the region of dead cells. This indicates that the cisplatin-induced death realized rather by the apoptotic pathway than by necrosis. Similar results, the initiation of apoptosis in tumor cells under the treatment with cisplatin, were previously demonstrated in a number of studies $[4,21,26]$. There are also papers reporting treatment with cisplatin led to necrosis or apoptosis and necrosis simultaneously in the same population of tumor cells $[27,28]$. There is an assumption that, depending on the level of cell damage caused by cisplatin, necrosis can take place either directly or as a result of an incomplete or defective apoptotic program [29-32]. Similar to experiments with trypan blue staining, in the experiments with flow cytometry a significant increase in the number of viable cells during simultaneous incubation with DMTU and cisplatin was observed. Since the addition of DMTU resulted in a significant decrease in the percentage of dead cells and did not increase the percentage of early apoptotic cells, we can deduce that DMTU plays the protective role for cells treated with cisplatin. The results are consistent with works of other researches showing the ability of DMTU to reduce the accumulation of singlet oxygen, hydroxyl radical [17], $\mathrm{H}_{2} \mathrm{O}_{2}$ [18], and block the activation of $p 53$, leading to weakening of p53 upregulated modulator of apoptosis alpha (PUMA- $\alpha$ ) production and suppression of the mitochondrial pathway of apoptosis during cisplatin treatment [16, 21].

The use of a specific sensor HyPer2 allowed to evaluate the contribution of $\mathrm{H}_{2} \mathrm{O}_{2}$ among a number of other ROS in the process of tumor cells death upon exposure to cisplatin.

The increase in the HyPer2 fluorescence intensity of cisplatin-treated cells as compared to control cells and the absence of such an increase in the experiments with cells with SypHer2 (see Figure 4) noted in the histograms indicated a significant increase in the amount of $\mathrm{H}_{2} \mathrm{O}_{2}$ in both viable and apoptotic cells. In a number of studies, it has been shown that the accumulation of intracellular $\mathrm{H}_{2} \mathrm{O}_{2}$ contributes significantly to enhanced apoptosis, although other mechanisms of its initiation cannot be excluded [4, 5, 33].

For example, $\mathrm{H}_{2} \mathrm{O}_{2}$, like other forms of ROS being important components of cellular signaling, can also cause DNA damage [33]. It should also be mentioned that the incubation of HeLa Kyoto-SypHer2 cells with cisplatin did not increase the fluorescence of the sensor, even leading to its decrease. Since the SypHer2 sensor is sensitive to changes in $\mathrm{pH}$, like HyPer2, being insensitive to $\mathrm{H}_{2} \mathrm{O}_{2}$ level changes, unlike HyPer2, their reactions are multidirectional: the apparent increase in fluorescence of $\mathrm{H}_{2} \mathrm{O}_{2}$ sensitive sensor has been partially weakened by intracellular $\mathrm{pH}$ changes. Addition of DMTU to cisplatin-treated cells led to a decrease in the level of $\mathrm{H}_{2} \mathrm{O}_{2}$ down to the values close to those in the control, and an increase of $\mathrm{pH}$ within the cell to the control values. It should be noted that since DMTU scavenge mainly the hydroxyl radical, an indirect reaction can be observed caused by the removal of the hydrogen peroxide precursor.

\section{Conclusion}

In our study, the participation of $\mathrm{H}_{2} \mathrm{O}_{2}$ in the response of tumor cells HeLa Kyoto to cytotoxic effects of cisplatin has been demonstrated. The removal of $\mathrm{H}_{2} \mathrm{O}_{2}$ caused by the presence of ROS scavenger DMTU leads to a significant increase in the viability of cisplatin-treated cells leading to viability similar to that for cells that were not exposed to the drug. The cisplatin-induced death is realized mainly due to the activation of the apoptotic pathway initiated by an increase in the amount of ROS, including $\mathrm{H}_{2} \mathrm{O}_{2}$.

Acknowledgement. The authors are grateful to I.V. Balalaeva (PhD) and E.V. Zagainova (MD, DSc) for providing research facilities, as well as to M.Yu. Kirillin $(\mathrm{PhD})$ for useful discussions.

Study funding. This study was supported by the grant of the Russian Foundation for Basic Research No.16-34-01112.

Conflict of interests. The authors have no conflict of interests to disclose.

\section{References}

1. Florea A.-M., Büsselberg D. Cisplatin as an anti-tumor drug: cellular mechanisms of activity, drug resistance and induced side effects. Cancers 2011; 3(4): 1351-1371, https:// doi.org/10.3390/cancers3011351.

2. Dasari S., Tchounwou P.B. Cisplatin in cancer therapy: molecular mechanisms of action. Eur J Pharmacol 2014; 740: 364-378, https://doi.org/10.1016/j.ejphar.2014.07.025.

3. Marullo R., Werner E., Degtyareva N., Moore B., 
Altavilla G., Ramalingam S.S., Doetsch P.W. Cisplatin induces a mitochondrial-ROS response that contributes to cytotoxicity depending on mitochondrial redox status and bioenergetic functions. PLoS One 2013; 8(11): e81162, https://doi. org/10.1371/journal.pone.0081162.

4. He F., Wang Q., Zheng X.L., Yan J.Q., Yang L., Sun H., Hu L.N., Lin Y., Wang X. Wogonin potentiates cisplatin-induced cancer cell apoptosis through accumulation of intracellular reactive oxygen species. Oncol Rep 2012; 28(2): 601-605, https://doi.org/10.3892/or.2012.1841.

5. Wang L., Chanvorachote P., Toledo D., Stehlik C., Mercer R.R., Castranova V., Rojanasakul Y. Peroxide is a key mediator of $\mathrm{Bcl}-2$ down-regulation and apoptosis induction by cisplatin in human lung cancer cells. Mol Pharmacol 2008; 73(1): 119-127, https://doi.org/10.1124/mol.107.040873.

6. Ahmad K.A., Iskandar K.B., Hirpara J.L., Clement M.-V., Pervaiz S. Hydrogen peroxide-mediated cytosolic acidification is a signal for mitochondrial translocation of Bax during druginduced apoptosis of tumor cells. Cancer Res 2004; 64(21): 7867-7878, https://doi.org/10.1158/0008-5472.can-04-0648.

7. Distelhorst C.W., Lam M., McCormick T.S. Bcl-2 inhibits hydrogen peroxide-induced ER Ca2 pool depletion. Oncogene 1996; 12(10): 2051-2055.

8. Yamakawa H., Ito Y., Naganawa T., Banno Y., Nakashima S., Yoshimura S., Sawada M., Nishimura Y., Nozawa Y., Sakai N. Activation of caspase-9 and -3 during $\mathrm{H}_{2} \mathrm{O}_{2}$-induced apoptosis of $\mathrm{PC} 12$ cells independent of ceramide formation. Neurol Res 2000; 22(6): 556-564, https:// doi.org/10.1080/01616412.2000.11740718.

9. Guo H., Aleyasin H., Dickinson B.C., HaskewLayton R.E., Ratan R.R. Recent advances in hydrogen peroxide imaging for biological applications. Cell Biosci 2014; 4(1): 64, https://doi.org/10.1186/2045-3701-4-64.

10. Belousov V.V., Fradkov A.F., Lukyanov K.A., Staroverov D.B., Shakhbazov K.S., Terskikh A.V., Lukyanov S. Genetically encoded fluorescent indicator for intracellular hydrogen peroxide. Nat Methods 2006; 3(4): 281-286, https:// doi.org/10.1038/nmeth866.

11. Kaminskyy V.O., Piskunova T., Zborovskaya I.B., Tchevkina E.M., Zhivotovsky B. Suppression of basal autophagy reduces lung cancer cell proliferation and enhances caspase-dependent and -independent apoptosis by stimulating ROS formation. Autophagy 2012; 8(7): 1032-1044, https://doi. org/10.4161/auto.20123.

12. Brilkina A.A., Peskova N.N., Dudenkova V.V., Gorokhova A.A., Sokolova E.A., Balalaeva I.V. Monitoring of hydrogen peroxide production under photodynamic treatment using protein sensor HyPer. $J$ Photochem Photobiol B 2018; 178: 296-301, https://doi.org/10.1016/j. jphotobiol.2017.11.020.

13. Markvicheva K.N., Bogdanova E.A., Staroverov D.B., Lukyanov S., Belousov V.V. Imaging of Intracellular hydrogen peroxide production with hyper upon stimulation of Hela cells with Egf. In: Methods in molecular biology. Humana Press; 2008; p. 76-83, https://doi.org/10.1007/978-1-59745-129-1_6.

14. Tyurin-Kuzmin P.A. Rol peroksida vodoroda $v$ regulyatsii polyarizatsii $i$ migratsii fibroblastov. Avtoref. dis. ... kand. biol. nauk [The role of hydrogen peroxide in the regulation of polarization and migration of fibroblasts. PhD Thesis]. Moscow; 2011.

15. Belova A.S., Orlova A.G., Balalaeva I.V., Antonova N.O., Maslennikova A.V., Mishina N.M., Zagaynova E.V. Hydrogen peroxide detection in viable and apoptotic tumor cells under action of cisplatin and bleomycin. Photonics \& Lasers in Medicine 2016; 5(2): 113-121, https://doi.org/10.1515/plm2015-0047.

16. Floriano-Sánchez E., Villanueva C., MedinaCampos O.N., Rocha D., Sánchez-González D.J., CárdenasRodríguez N., Pedraza-Chaverrí J. Nordihydroguaiaretic acid is a potent in vitro scavenger of peroxynitrite, singlet oxygen, hydroxyl radical, superoxide anion and hypochlorous acid and prevents in vivo ozone-induced tyrosine nitration in lungs. Free Radic Res 2006; 40(5): 523-533, https://doi. org/10.1080/10715760500419365.

17. Kim S., Yamamoto K., Nakamura Y., Otoyo Y., Yamatodani A. A possible mechanism of cisplatin-induced tumor necrosis factor (TNF)- $\alpha$ production in murine macrophages. Pharmacology \& Pharmacy 2013; 4(2): 146151, https://doi.org/10.4236/pp.2013.42021.

18. Curtis W.E., Muldrow M.E., Parker N.B., Barkley R., Linas S.L., Repine J.E. N,N'-dimethylthiourea dioxide formation from $\mathrm{N}, \mathrm{N}$ '-dimethylthiourea reflects hydrogen peroxide concentrations in simple biological systems. Proc Natl Acad Sci USA 1988; 85(10): 3422-3425, https://doi.org/10.1073/ pnas.85.10.3422.

19. Toth K.M., Clifford D.P., Berger E.M., White C.W., Repine J.E. Intact human erythrocytes prevent hydrogen peroxide-mediated damage to isolated perfused rat lungs and cultured bovine pulmonary artery endothelial cells. J Clin Invest 1984; 74(1): 292-295, https://doi.org/10.1172/jci111414.

20. Santos N.A., Bezerra C.S., Martins N.M., Curti C., Bianchi M.L., Santos A.C. Hydroxyl radical scavenger ameliorates cisplatin-induced nephrotoxicity by preventing oxidative stress, redox state unbalance, impairment of energetic metabolism and apoptosis in rat kidney mitochondria. Cancer Chemother Pharmacol 2007; 61(1): 145-155, https:// doi.org/10.1007/s00280-007-0459-y.

21. Jiang M., Wei Q., Pabla N., Dong G., Wang C.Y., Yang T., Smith S.B., Dong Z. Effects of hydroxyl radical scavenging on cisplatin-induced p53 activation, tubular cell apoptosis and nephrotoxicity. Biochem Pharmacol 2007; 73(9): 1499-1510, https://doi.org/10.1016/j.bcp.2007.01.010.

22. dos Santos N.A., Martins N.M., Curti C., Pires Bianchi M. de L., dos Santos A.C. Dimethylthiourea protects against mitochondrial oxidative damage induced by cisplatin in liver of rats. Chem Biol Interact 2007; 170(3): 177-186, https:// doi.org/10.1016/j.cbi.2007.07.014.

23. Baek S.M., Kwon C.H., Kim J.H., Woo J.S., Jung J.S., Kim Y.K. Differential roles of hydrogen peroxide and hydroxyl radical in cisplatin-induced cell death in renal proximal tubular epithelial cells. J Lab Clin Med 2003; 142(3): 178-186, https:// doi.org/10.1016/s0022-2143(03)00111-2.

24. Shirmanova M.V., Druzhkova I.N., Lukina M.M., Matlashov M.E., Belousov V.V., Snopova L.B., Prodanetz N.N., Dudenkova V.V., Lukyanov S.A., Zagaynova E.V. Intracellular $\mathrm{pH}$ imaging in cancer cells in vitro and tumors in vivo using the new genetically encoded sensor SypHer2. Biochim Biophys Acta 2015; 1850(9): 1905-1911, https://doi.org/10.1016/j. bbagen.2015.05.001.

25. Belova A.S., Orlova A.G., Brilkina A.A., Maslennikova A.V. The sensitivity of Hela Kyoto cell line transfected with sensor HyPer2 to cisplatin. Sovremennye tehnologii v medicine 2014; 6(4): 7-13.

26. Brozovic A., Ambriović-Ristov A., Osmak M. The relationship between cisplatin-induced reactive oxygen species, glutathione, and BCL-2 and resistance to 


\section{EXPERIMENTAL INVESTIGATIONS}

cisplatin. Crit Rev Toxicol 2010; 40(4): 347-359, https://doi. org/10.3109/10408441003601836.

27. Sancho-Martínez S.M., Piedrafita F.J., CannataAndía J.B., López-Novoa J.M., López-Hernández F.J. Necrotic concentrations of cisplatin activate the apoptotic machinery but inhibit effector caspases and interfere with the execution of apoptosis. Toxicol Sci 2011; 122(1): 73-85, https://doi. org/10.1093/toxsci/kfr098.

28. Pestell K.E., Hobbs S.M., Titley J.C., Kelland L.R., Walton M.I. Effects of p53 status on sensitivity to platinum complexes in a human ovarian cancer cell line. Mol Pharmacol 2000; 57(3): 503-511, https://doi.org/10.1124/mol.57.3.503.

29. Segal-Bendirdjian E., Jacquemin-Sablon A. Cisplatin resistance in a murine leukemia cell line is associated with a defective apoptotic process. Exp Cell Res 1995; 218(1): 201212, https://doi.org/10.1006/excr.1995.1148.
30. Gonzalez V.M., Fuertes M.A., Alonso C., Perez J.M. Is cisplatin-induced cell death always produced by apoptosis? Mol Pharmacol 2001; 59(4): 657-663, https://doi.org/10.1124/ mol.59.4.657.

31. Cepeda V., Fuertes M.A., Castilla J., Alonso C., Quevedo C., Pérez J.M. Biochemical mechanisms of cisplatin cytotoxicity. Anticancer Agents Med Chem 2007; 7(1): 3-18, https://doi.org/10.2174/187152007779314044.

32. Eguchi Y., Shimizu S., Tsujimoto Y. Intracellular ATP levels determine cell death fate by apoptosis or necrosis. Cancer Res 1997; 57(10): 1835-1840.

33. Tenopoulou M., Doulias P.T., Barbouti A., Brunk U., Galaris D. Role of compartmentalized redox-active iron in hydrogen peroxide-induced DNA damage and apoptosis. Biochem J 2005; 387(3): 703-710, https://doi.org/10.1042/ bj20041650. 